\title{
SURGICAL REPAIR OF MULTIPLE TIBIAL FRACTURE IN A WOLF WHELF (CANIS LUPUS) BY BONE PLATING
}

\section{R.V. Suresh Kumar and Makkena Sreenu}

Assistant Professor, Department of Surgery and Radiology, College of Veterinary Science, Tirupati, Andhra Pradesh 517502, India.

Fractures of limbs are common in domestic as well as in wild animals. Fracture reduction, perfect immobilization and postoperative care will decide the success rate in any fracture management in non-infected cases. We present here a successful surgical repair of tibial fracture with bone plating in a Wolf whelf.

A eight month old male Wolf pup (Canis lupus) belonging to S.V. Zoological Park, Tirupati was presented to the surgical ward with a complaint of broken right hind limb. The animal was unable to walk and bear weight on right hind limb. Temperature, pulse and respiratory rates were within normal physiological limits. On palpation, swelling, crepitus and pain was observed. At the proximal third of tibial shaft. Radiographic examination revealed complete, multiple fracture of proximal third of right tibial shaft. Fractured bone chips were also noticed (Fig. 1). Based on these findings, it was decided to perform surgery.

Triflupromazine hydrochloride @ $2 \mathrm{mg} / \mathrm{kg}$ body weight was given intramuscularly as preanaesthetic 15 minutes before surgery. The animal was anaesthetized with $25 \%$ solution of Thiopentone

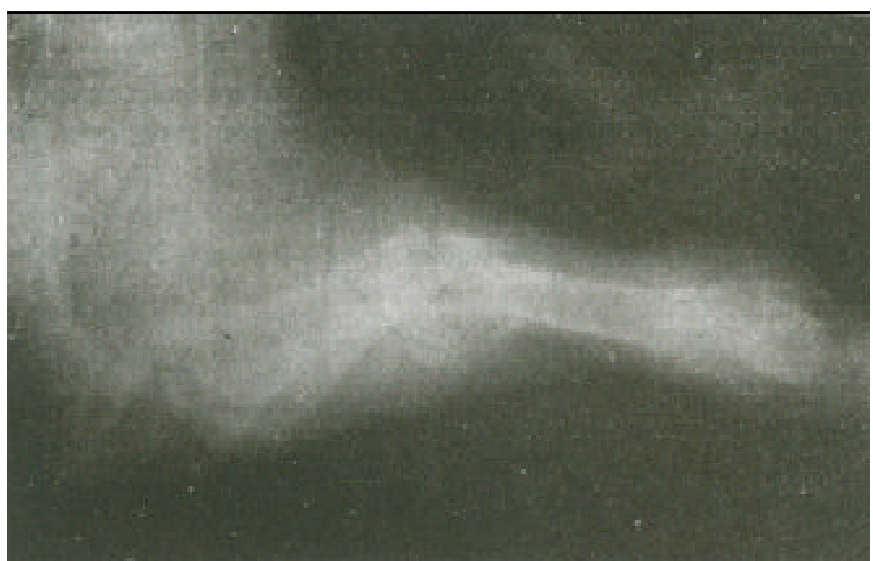

Figure 1. Skiagram showing complete multiple fracture of proximal tibia.

Received on 8 October 1999

Accepted on 4 March 2000

sodium @ 25 mg/kg body weight given intravenously. The tibia was approached from medial aspect by incising the skin and separating muscles. After avoiding blood vessels and nerves, proximal and distal fracture segments were isolated. Sharp edges were removed. The two fractured ends were kept in alignment and immobilized and six holed sherman bone plate was applied over it. The screws were snugly fit up to opposite cortex. The plate was kept in position by wires (Fig. 2). Demineralized bone matrix powder was poured at the fractured site to enhance healing and bone formation. Streptopenicillin powder was applied over the operative site after removing blood clots. The muscles were sutured using no.1 chromic catgut by interrupted suture technique. Shin incision was closed using no.1 silk by horizontal mattress suture technique. Tincture benzoin seal was applied to the suture line. Streptopenicillin 0.5 grams and Diclofaenac sodium $2 \mathrm{ml}$. was given intramuscularly for five post operative days. Modified Thomas splint was applied to the limb for perfect immobilization. The animal made uneventful recovery without any complications.

\section{Acknowledgements}

The authors are highly thankful to the Authorities and Veterinary Surgeon, S.V. Zoological Park for their co-operation for this work.

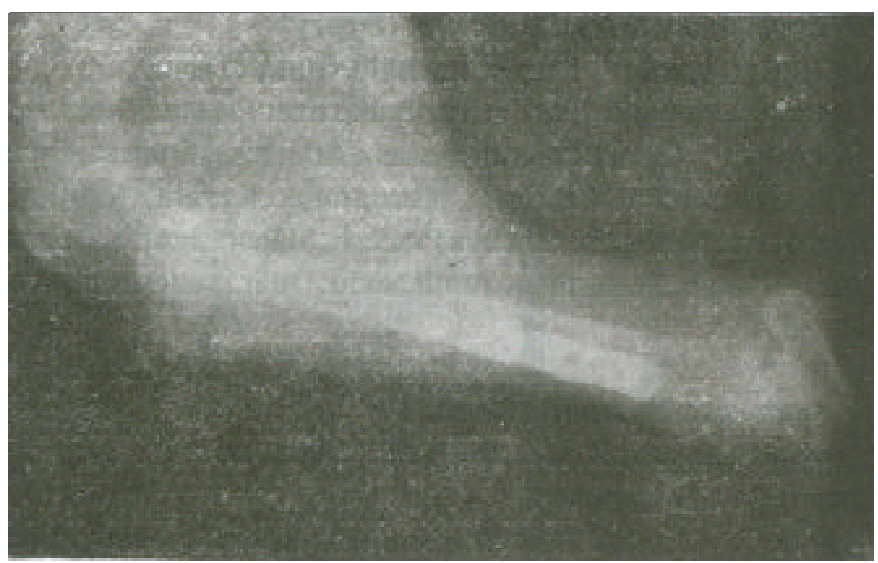

Figure 2. Skiagram showing bone plating in situ. 